\title{
What causes the change in energy demand in the economy?:
}

\section{The role of technological change}

\author{
Shinichiro Okushima ${ }^{\mathrm{a},{ }^{* 1}}$ and Makoto Tamura ${ }^{\mathrm{b},{ }^{* 2}}$
}

a Graduate School of Systems and Information Engineering, University of Tsukuba, 1-1-1, Ten-nodai, Tsukuba-science-city, Ibaraki, 305-8573, Japan

b Institute for Global Change Adaptation Science, Ibaraki University, 2-1-1, Bunkyo, Mito-city, Ibaraki, 310-8512, Japan

\begin{abstract}
This paper proposes a simple and theoretically clear approach to the estimation of technological change in a multisector general equilibrium framework. This study employs the Multiple Calibration Decomposition Analysis (MCDA) to evaluate technological change that is responsible for changes in energy use and carbon dioxide emissions in the Japanese economy in the oil crises period from 1970 to 1985 . The MCDA serves as an elementary way of separating structural change due to technological change from that due to price substitution effects, capturing the interdependence among economic sectors. The empirical result provides a better understanding of the effects on the economy of technological change in that significant period.
\end{abstract}

JEL classification: D57; D58; O30; Q40; Q50

Keywords: Calibration; Carbon dioxide emissions; Energy use; General equilibrium model; Technological change

\footnotetext{
${ }^{* 1}$ E-mail address: okushima@sk.tsukuba.ac.jp (S. Okushima). Tel./fax: +81-29-853-5226.

*2 E-mail address: tamura@mx.ibaraki.ac.jp (M. Tamura). Tel./fax: +81-29-228-8805.
} 


\section{Introduction}

There has been renewal of interest in the energy demand analysis, generated by the recent fluctuation of energy prices or in the context of global climate change. Change in energy usage patterns is caused by many factors. In particular, technological change is a major determinant of changes in energy use, and by the same token, of change in carbon dioxide $\left(\mathrm{CO}_{2}\right)$ emissions. There is still room for improvement in the estimation of technological change, even though several decades have passed since Solow's seminal papers appeared. The estimation is burdensome; nevertheless, it is indispensable to understand the contribution of factors to structural change over time.

This paper proposes a simple and theoretically clear approach to the estimation of technological change in a multisector general equilibrium framework. One of the most familiar approaches is the Total Factor Productivity measurement or the Growth Accounting method developed by Solow (1957), which decomposes output growth into measured increases in factor inputs and technical change (see, e.g., Denison, 1967; Jorgenson and Griliches, 1967). This method is of great significance with regard to the explicit integration of economic theory into such decomposition (Griliches, 1996). Motivated by Solow's theme, Okushima and Tamura (2007) develops a new decomposition methodology -the Multiple Calibration Decomposition Analysis (MCDA). This methodology serves as an elementary way of segregating structural change due to technological change from that due to price substitution effects, capturing the interdependence among economic sectors or factor inputs in a general equilibrium framework. This paper then 
applies the MCDA to the estimation of technological change that affects energy use and $\mathrm{CO}_{2}$ emissions in the Japanese economy.

It is notable that the method also continues the tradition of the Input-Output (I-O) analysis. In the I-O framework, Structural Decomposition Analysis (SDA) has recently been popular as a tool for decomposition (Rose and Casler, 1996) because it overcomes the static features of I-O analysis and enables evaluation of structural change. Nonetheless, as Rose and Casler (1996) points out, “a rigorous grounding in economic theory is lacking for SDA". The method may provide some additional theoretical underpinnings for I-O analysis or SDA. Furthermore, the method has an advantage regarding data availability or efficiency. Although the attempt to perform econometric studies often suffers from data insufficiency, our approach has need of only a two-period dataset. Hence, it is a practical alternative to econometric approaches.

The remainder of the paper is structured as follows. Section 2 explains the methodology. Sections 3 and 4 apply this method to an empirical case, the Japanese economy following the oil crises between 1970 and 1985, with the object of evaluating technological change that is responsible for changes in energy use and $\mathrm{CO}_{2}$ emissions. The final section presents concluding remarks.

\section{Methodology}

The methodology in this paper is an application of the Multiple Calibration Decomposition Analysis (MCDA) to the estimation of technological change. The MCDA, developed by Okushima 
and Tamura (2007), enables us to disentangle individual causes from a series of simultaneous shocks to an economy consistent with the general equilibrium theory.

The MCDA can precisely decompose change in factor inputs (CFI) into two components, price substitution effects (PS) and other types of technological change (TC). ${ }^{1}$ Generally, in the MCDA, change in factor inputs per unit of output (change in input coefficients) $\Delta \mathbf{A}$ can be described as:

$$
\Delta \mathbf{A}=\lambda f(\Delta \mathbf{p}, \Delta),
$$

where $\Delta \mathbf{p}$ is the change in relative prices, $\Delta \lambda$ is the technological change, and $f($.$) is the$ underlying model. In the analysis, $f($.$) is the constant elasticity of substitution (CES) production$ function, which yields various types of production structure with the substitution parameter (elasticity of substitution) $\sigma$. The substitution parameter $\sigma$ denotes the extent of input substitution. A larger $\sigma$ makes input substitution more likely, and there is no substitution between inputs when $\sigma=0$. The CES production function corresponds to the Leontief production function when $\sigma$ equals zero and the Cobb-Douglas production function when $\sigma$ equals one as the special case. It is noticeable that the MCDA methodology can use many types of production functions, and can apply in the case where elasticities are different in each sector and between inputs using nested production functions (see, Okushima and Tamura, 2007). Nevertheless, for the purpose of this paper, the analysis employs rather a simplified model as the production function $f($.$) ; a single tier and$

\footnotetext{
${ }^{1}$ In the analysis, as in relevant literature on this subject, structural change (total change) is defined as the change in factor inputs per unit of output (CFI), which is identical to the change in input coefficients in $\mathrm{I}-\mathrm{O}$ tables. This definition is a purely economic one.
} 
constant elasticities of substitution in all sectors and between inputs.

This paper applies the MCDA methodology to the estimation of technological change. Let us consider the behavior of industries. Their production functions are given by constant-returns-to-scale CES functions, and they are assumed to act so as to maximize their profits in competitive markets. Capital $(K)$ and labor $(L)$ are the primary factors of production. Hence, factor inputs per unit of output (hereafter, factor inputs) in the initial period ( $t-1)$ are derived as in Eq. (2):

$$
\frac{x_{i j}^{t-1}}{X_{j}^{t-1}}=\lambda_{i j}^{t-1} \beta_{j}^{\sigma_{j}-1}\left(\alpha_{i j} \frac{p_{j}^{t-1}}{p_{i}^{t-1}}\right)^{\sigma_{j}}, i=1, \ldots, n, K, L ; j=1, \ldots, n,
$$

where $x_{i j}^{t-1}$ is the input of $i$ by the sector $j$ in $t-1, X_{j}^{t-1}$ is the output of the sector $j$ in $t-1, p_{j}^{t-1}$ or $p_{i}^{t-1}$ is the price of the good $j$ or $i$ in $t-1, \sigma_{j}$ is the elasticity of substitution of the sector $j, \lambda_{i j}^{t-1}$ is the TC parameter in $t-1, \alpha_{i j}$ is the share parameter $\left(\sum_{i} \alpha_{i j}=1\right)$, and $\beta_{j}$ is the scale parameter of the CES functions.

The parameter $\lambda_{i j}$ embodies TC. $\lambda_{i j}^{t-1}$ is set at unity. This is normalization because only changes of $\lambda_{i j}$ are relevant to our study. $p_{j}^{t-1}$ and $p_{i}^{t-1}$ are also one because they are from actual price data, normalized so that the prices in the initial period are one (see Section 3). When the values of $x_{i j}^{t-1}$ and $X_{j}^{t-1}$ are obtained from the dataset, and the substitution parameters $\sigma_{j}$ are exogenously given, all parameters of the production functions, $\alpha_{i j}$ and $\beta_{j}$, are determined to reproduce the actual economic structure in $t-1$ as an equilibrium. This is the same procedure followed in the conventional single calibration technique (see, Mansur and Whalley, 1984; Shoven and Whalley, 
1984, 1992; Dawkins et al., 2001). Then the production functions are specified. The parameters, $\alpha_{i j}$, $\beta_{j}$, and $\sigma_{j}$, are assumed to be unchanged over the periods.

It is noteworthy that the method uses another period's dataset to specify the TC parameters. The factor inputs in the terminal period $(t)$ are given by Eq. (3):

$$
\frac{x_{i j}^{t}}{X_{j}^{t}}=\lambda_{i j}^{t} \beta_{j}^{\sigma_{j}-1}\left(\alpha_{i j} \frac{p_{j}^{t}}{p_{i}^{t}}\right)^{\sigma_{j}},
$$

where $x_{i j}^{t}$ is the input of $i$ by the sector $j$ in $t, X_{j}^{t}$ is the output of the sector $j$ in $t$, $p_{j}^{t}$ or $p_{i}^{t}$ is the price of the good $j$ or $i$ in $t$, and $\lambda_{i j}^{t}$ is the TC parameter in $t$. When the values of $x_{i j}^{t}, X_{j}^{t}$, and $p_{i}^{t}$ are obtained from the dataset, the TC parameters $\lambda_{i j}^{t}$ are endogenously determined to replicate the economic structure in $t$ as another equilibrium. In other words, $\lambda_{i j}^{t}$ are chosen to fill the gap between the counterfactual point associated with the price change under the specified production functions and the actual equilibrium in the terminal period.

In the analysis, the CFI is described as the change from the factor inputs in the initial period as in Eq. (2) to the ones in the terminal period as in Eq. (3):

$$
\frac{\Delta\left(x_{i j} / X_{j}\right)}{\left(x_{i j} / X_{j}\right)}=\frac{\Delta \lambda_{i j}}{\lambda_{i j}}+\sigma_{j} \frac{\Delta\left(p_{j} / p_{i}\right)}{\left(p_{j} / p_{i}\right)} .
$$

The TC can then be obtained as:

$$
\begin{aligned}
\frac{\Delta \lambda_{i j}}{\lambda_{i j}} & =\frac{\Delta\left(x_{i j} / X_{j}\right)}{\left(x_{i j} / X_{j}\right)}-\sigma_{j} \frac{\Delta\left(p_{j} / p_{i}\right)}{\left(p_{j} / p_{i}\right)}, \\
\Leftrightarrow \mathrm{TC} & =\mathrm{CFI}-\mathrm{PS} .
\end{aligned}
$$

As in Eq. (5), TC equals CFI minus PS. TC embodies the part of the factor input change that cannot be explained by price substitution effects. Hence, when $\lambda_{i j}^{t}>1$, factor-augmenting 
technological change occurs, while when $\lambda_{i j}^{t}<1$, factor-diminishing technological change occurs. On the other hand, PS, which depends on the elasticity of substitution $\sigma_{j}$ and the change in relative prices over the periods, embodies the price substitution effects on the production functions. As has been explained above, $\sigma_{j}$ represents the extent of substitution. When $\sigma_{j}=0$, there is no price substitution (PS=0); TC equals CFI.

Fig. 1 illustrates the concept of the method, which is consistent with the production theory in microeconomics. From a theoretical viewpoint, TC represents a shift of the production functions, and PS represents the change in factor inputs along the production functions. In contrast to I-O analysis, in which technological change is measured without respect to price change, our method can explicitly incorporate price substitution effects into the evaluation. The prominent feature of the method is that it has clear theoretical underpinnings, and allows the estimated parameters to be interpreted in a theoretically meaningful way.

Further, Eq. (3) can also be expressed as Eq. (6) using matrices:

$$
\begin{aligned}
& \left(\begin{array}{ccc}
\frac{x_{11}^{t}}{X_{1}^{t}} & \cdots & \frac{x_{1 n}^{t}}{X_{n}^{t}} \\
\vdots & \frac{x_{i j}^{t}}{X_{j}^{t}} & \vdots \\
\frac{x_{n 1}^{t}}{X_{1}^{t}} & \cdots & \frac{x_{n n}^{t}}{X_{n}^{t}}
\end{array}\right)=\left(\begin{array}{ccc}
\left(\frac{1}{p_{1}^{t}}\right)^{\sigma} & \cdots & 0 \\
\vdots & \left(\frac{1}{p_{i}^{t}}\right)^{\sigma} & \vdots \\
0 & \cdots & \left(\frac{1}{p_{n}^{t}}\right)^{\sigma}
\end{array}\right)\left(\begin{array}{cccc}
\lambda_{11}^{t} \beta_{1}^{\sigma-1} \alpha_{11}{ }^{\sigma} & \cdots & \lambda_{1 n}^{t} \beta_{n}{ }^{\sigma-1} \alpha_{1 n}{ }^{\sigma} \\
\vdots & \lambda_{i j}^{t} \beta_{j}{ }^{\sigma-1} \alpha_{i j}{ }^{\sigma} & \vdots \\
\lambda_{n 1}^{t} \beta_{1}^{\sigma-1} \alpha_{n 1}{ }^{\sigma} & \cdots & \lambda_{n n}^{t} \beta_{n}{ }^{\sigma-1} \alpha_{n n}{ }^{\sigma}
\end{array}\right)\left(\begin{array}{ccc}
p_{1}^{t \sigma} & \cdots & 0 \\
\vdots & p_{j}^{t \sigma} & \vdots \\
0 & \cdots & p_{n}^{t \sigma}
\end{array}\right), \\
& \Leftrightarrow \mathbf{A}=\hat{\mathbf{Q}} \mathbf{L} \hat{\mathbf{P}} .
\end{aligned}
$$

Intriguingly, Eq. (6) is analogous to the RAS matrices in I-O analysis (see, e.g., Bacharach, 1970). In the RAS terminology, $\hat{\mathbf{Q}}$ is regarded as the $\hat{\mathbf{R}}$ matrix, which represents 
substitution effects, and $\hat{\mathbf{P}}$ is regarded as the $\hat{\mathbf{S}}$ matrix, which represents fabrication effects.

[Insert Fig. 1 here]

\section{Energy consumption}

This paper applies the method to an actual case, the Japanese economy in the period from 1970 to 1985, when skyrocketing oil prices had a great influence on the Japanese economy. This situation then offers a typical case for application of the method, which can evaluate the extent to which the Japanese economy was affected by technological change.

This section analyzes the change in energy consumption. Data from 1970 to 1985 are used in the analysis. The sectors are classified into five industries and four energy inputs (see the notes accompanying Table 1 for more details). Nominal outputs (factor inputs) are obtained from the 1970-75-80 and 1985-90-95 Linked Input-Output Tables (Management and Coordination Agency). Prices of goods and services are from the Domestic Wholesale Price Index (Bank of Japan) or Deflators on Outputs of National Accounts (Economic Planning Agency). Capital and labor prices are estimated following Ito and Murota (1984). In our study, units of goods, services and factors are defined as those that cost one Japanese yen in 1970. This is the units convention, originally adopted by Harberger (1962), and widely used since (Shoven and Whalley, 1984, 1992; Dawkins et al., 2001). The convention enables us to obtain consistent units across time. Hence, real outputs (factor inputs) are obtained by deflating nominal values by the corresponding prices.

Tables 1-3 show technological change (TC) in the cases where $\sigma=0, \sigma=0.5$, and $\sigma=$ 
1 , respectively. TC, which is represented as a percentage change, varies depending on $\sigma$. First, in the case where $\sigma=0$, there is no price substitution. Hence, TC explains all the CFI, i.e., TC equals structural change. Next, as shown in the tables, TC varies according to changes in $\sigma$. A larger $\sigma$ makes price substitution effects more likely. Therefore, the more $\sigma$ increases, the larger the proportion of CFI that is explained by PS.

This section analyzes the case of oil as an example because TC for oil is considered to have been greatly affected by the oil crises. In the case where $\sigma=0$ (no price substitution) in Table 1, all sectors have negative TC for oil. This means that factor inputs of oil decreased in all sectors, implying that oil-saving technological change occurred between 1970 and 1985.

However, price substitution effects occurred in reality. Tables 2 and 3 take these effects into consideration. As the tables indicate, TC for oil increases as $\sigma$ becomes larger. In the case where $\sigma=0.5$ in Table 2, all sectors except EII still have negative TC for oil. However, Table 3 shows that all sectors have positive TC for oil, which means that factor-augmenting technological change occurred. This implies that, in the case where $\sigma=1$, price substitution effects were expected to induce a larger decrease in factor inputs of oil, whereas they did not decrease to the degree that was expected from these effects. The decrease in factor inputs of oil over the periods could be explained by price substitution effects (PS) rather than technological change (TC) in the neighborhood of $\sigma=1$.

In the analysis, elasticities of substitution are arbitrarily changed between zero and one for the purpose of this study. In practice, estimated parameters, and more elaborate production 
structure, should be used for empirical analyses. In the Japanese case, the existing literature indicates that most elasticities of substitution are below one (see, e.g., Tokutsu, 1994). In addition, Okushima and Tamura (2007) employs a full-fledged two-tier KLEM model, which is composed of capital $K$, labor $L$, energy aggregate $E$, and material aggregate $M$, as well as energy and material subaggregates, and empirically shows that oil-saving technological change occurred in the oil crises period. This is close to the smaller $\sigma$ case in this paper. Okushima and Tamura (2007) indicates that the result would reflect various technological innovations taking place during that period; for instance, the continuous casting or waste heat recovery in the iron and steel industry, and waste heat recovery equipment of plants in the chemical industry (see, e.g., MITI, 1985).

The analysis demonstrates the extent to which energy demand was affected by technological change in the Japanese economy between 1970 and 1985. It shows that technological change is of great importance to understand change in energy demand in the economy and that substitution elasticity is essential for the estimation.

[Insert Table 1 here]

[Insert Table 2 here]

[Insert Table 3 here]

\section{4. $\mathrm{CO}_{2}$ emissions}

This section analyzes the change in carbon dioxide $\left(\mathrm{CO}_{2}\right)$ emissions in the Japanese economy from 1970 to 1985 . This analysis evaluates the contribution of technological change to the 
change in $\mathrm{CO}_{2}$ emissions in the oil crises period when the escalation of oil prices greatly affected the Japanese economy. It provides a typical example on which to apply our method and has some implications for current Japanese environmental policy.

The result regarding energy demand in Section 3 forms the basis of the analysis of $\mathrm{CO}_{2}$ emissions. This analysis may be regarded as an extension of Structural Decomposition Analysis (SDA) in that it deals with the decomposition of both a factor input matrix (input coefficient matrix) and a final demand vector (Rose and Casler, 1996; Rose, 1999; Hoekstra and van den Bergh, 2002; Hoekstra, 2005). One of the advantages is that it can allow the evaluation of volume considering both direct and indirect effects. ${ }^{2}$ This paper decomposes a factor input matrix based on the MCDA methodology, using the result in Section 3.

The formulation is based on Okushima and Tamura (2007). In the analysis, $\mathrm{CO}_{2}$ emissions are expressed as:

$$
\boldsymbol{\Pi}_{\text {ТОT }}=\mathbf{C}(\mathbf{I}-\mathbf{A})^{-1} \mathbf{Y}
$$

where $\boldsymbol{\Pi}_{T O T}$ is the $\mathrm{CO}_{2}$ emission vector [carbon metric tons; t-C], $\mathbf{C}$ is the $\mathrm{CO}_{2}$ emission coefficient matrix [t-C/Yen], $\mathbf{I}$ is an identity matrix, $\mathbf{A}$ is the factor input matrix (input coefficient matrix), $(\mathbf{I}-\mathbf{I A})^{-1}\left(\equiv^{-}\right)$is the Leontief inverse matrix, and $\mathbf{Y}$ is the final demand vector. The emission intensity matrix is defined as $\mathbf{\Pi} \equiv \mathbf{C}(\mathbf{I}-\mathbf{A})^{-1}$.

The change in $\mathrm{CO}_{2}$ emissions over periods is given by:

\footnotetext{
${ }^{2}$ Another decomposition technique is Index Number Analysis (INA) or Index Decomposition (ID). Although ID requires less data than SDA, it cannot distinguish direct effects from indirect effects. See
} 


$$
\Delta \boldsymbol{\Pi}_{T O T}=\Delta \boldsymbol{\Pi} \mathbf{Y}+\boldsymbol{\Pi} \Delta \mathbf{Y}+\varepsilon,
$$

where $\Delta$ is the derivative between periods and $\varepsilon$ is an interaction term. Each source of the change represents a comparative static result, while keeping the other factors constant. From Eq. (8), the change in $\mathrm{CO}_{2}$ emissions is decomposed into three major components: a Leontief inverse effect (KLEM effects) due to changes in the factor input matrix, a final demand effect attributable to changes in a final demand vector, and an interaction effect (see, e.g., Casler and Rose, 1998; Hoekstra and van den Bergh, 2002; Hoekstra, 2005).

The Leontief inverse effect is further subdivided into the various types of KLEM effects. The change in emission intensity matrix can be approximately written as $\Delta \mathbf{\Pi} \cong \boldsymbol{\Pi}^{t-1} \Delta \mathbf{A} \overline{\boldsymbol{\Pi}}^{t-1}$ (see, Casler and Rose, 1998; Rose, 1999); hence the change in $\mathrm{CO}_{2}$ emissions resulting from the KLEM effects is given by:

$$
\Delta \boldsymbol{\Pi}_{T O T, K L E M} \cong\left(\boldsymbol{\Pi}^{t-1} \Delta \mathbf{A} \bar{\Pi}^{t-1}\right) \mathbf{Y} .
$$

The method can divide the change in the factor input matrix (the $i j$ th element is $a_{i j}^{t}-a_{i j}^{t-1}$ ) into the matrices reflecting the various effects by extending the individual elements obtained from the result in Section 3 into the corresponding matrices with zeros elsewhere:

$$
\Delta \mathbf{A}=\Delta \mathbf{A}_{K}^{\mathrm{TC}}+\Delta \mathbf{A}_{K}^{\mathrm{PS}}+\Delta \mathbf{A}_{L}^{\mathrm{TC}}+\Delta \mathbf{A}_{L}^{\mathrm{PS}}+\Delta \mathbf{A}_{E}^{\mathrm{TC}}+\Delta \mathbf{A}_{E}^{\mathrm{PS}}+\Delta \mathbf{A}_{M}^{\mathrm{TC}}+\Delta \mathbf{A}_{M}^{\mathrm{PS}}
$$

where $\Delta \mathbf{A}_{I}^{\mathrm{TC}}(I=K, L, E, M)$ represents the technological change (TC), and $\Delta \mathbf{A}_{I}^{\mathrm{PS}}(I=K, L, E, M)$

Ang and Zhang (2000), Hoekstra and van den Bergh (2003), and Hoekstra (2005) for more details. 
represents the price substitution (PS). Here, the subscript $K$ means capital, $L$ labor, $E$ energy (COAL, OIL, GAS, and ELC), and M materials (AGM, EII, MAC, OMF, and SER). The KLEM effects for the change in $\mathrm{CO}_{2}$ emissions are given by inserting Eq. (10) into Eq. (9). For more details, see Okushima and Tamura (2007), and Casler and Rose (1998).

The data sources and classifications in the analysis are the same as earlier. $\mathrm{CO}_{2}$ emissions are calculated by multiplying the $\mathrm{CO}_{2}$ emission coefficient matrix by the standard monetary I-O transactions. The energy inputs that lead to $\mathrm{CO}_{2}$ emissions are coal, oil, and gas while the use of electricity does not directly generate $\mathrm{CO}_{2} \cdot \mathrm{CO}_{2}$ emissions in Japan, which are obtained by multiplying the energy consumption by their corresponding emission coefficients (IEA, 1999), rose by 45 (204 to 249) million carbon metric tons [Mt-C]: a 22\% increase between 1970 and 1985.

Table 4 shows the decomposition of the change in $\mathrm{CO}_{2}$ emissions when the substitution elasticity ( $\sigma$ ) is zero. Note that TC equals CFI, i.e., structural change, when $\sigma=0$, as previously explained. Table 4 indicates that the final demand effect is the major contributor to the increase in $\mathrm{CO}_{2}$ emissions, which is generally observed in a continuously growing economy. It also shows that some of the KLEM effects serve as moderating influences on the increase in emissions. In particular, the negative contribution of the labor TC (=CFI) stands out, resulting from the increase in labor productivity. The energy TC $(=\mathrm{CFI})$ is also a slightly negative contributor. By contrast, the capital and material TC (=CFI) contribute substantially to the emission increase. The former reflects the continuously increasing trend in capital intensity in the Japanese economy. These results are consistent with those of other empirical literature on the Japanese economy (see, e.g., Tokutsu, 
1998; Kagawa and Inamura, 2001).

However, the substitution elasticity $\sigma$ is the key factor in evaluating the contribution of TC to the change in $\mathrm{CO}_{2}$ emissions. Fig. 2 depicts the sensitivity of the result when the substitution elasticity varies. The analysis fluctuates $\sigma$ in the range from 0 to 1 with a 0.1 interval. Fig. 2 shows the upper and lower bounds of the result and indicates the cases where $\sigma$ is $0,0.5$, and 1 . The extreme cases, where $\sigma$ is 0 and 1, correspond to the upper and lower bounds. As in Eq. (5), TC is determined in conjunction with both CFI and PS. The change in substitution elasticities alters the volumes of PS, which have a ripple effect on the values of TC. In this sense, TC depends on the substitution elasticity value. Fig. 2 illustrates that the contribution of the capital and material TC decreases as the elasticity increases, while that of the labor and energy TC increases. The energy TC has positive influence on the rise in $\mathrm{CO}_{2}$ emissions when the substitution elasticity is large. In other words, the negative contribution of the energy CFI in Table 4 could be explained by price substitution effects (PS) rather than technological change (TC). This corresponds to the result in Section 3, which shows that factor-augmenting technological change for oil occurred in the sectors with the larger $\sigma$.

This paper applies a simplified model to evaluating the role of technological change in the change in $\mathrm{CO}_{2}$ emissions during the period from 1970 to 1985 . Table 5 compares the results with those of previous empirical literature. Okushima and Tamura (2007) shows that the capital and material TC are the major contributors to the $\mathrm{CO}_{2}$ emission increase while the labor and energy TC mitigate the increase. Although the models and targeted periods are different, Okushima and 
Tamura (2007)'s result is close to the estimate with the smaller $\sigma$ (see also Fig. 2).

This analysis concludes that technological change is pivotal to understanding the change in $\mathrm{CO}_{2}$ emissions and that substitution elasticity is important for the estimation. The analysis, albeit with a simple model, provides a fundamental understanding of elasticity sensitivity and confirms that better elasticity estimates are crucial to the advancement of the field, as Shoven and Whalley $(1984,1992)$ remarks.

[Insert Table 4 here]

[Insert Fig. 2 here]

[Insert Table 5 here]

\section{Conclusion}

This paper suggests a simple and theoretically clear methodology for the estimation of technological change in a multisector general equilibrium framework. This study uses the proposed method to identify the determinants of changes in energy usage patterns and $\mathrm{CO}_{2}$ emissions in the Japanese economy in the period from 1970 to 1985 . This empirical analysis illustrates the principal strength of the methodology, which is to provide a better understanding of the extent to which the economy was affected by technological change. The results show the importance of technological change in the context of the changes in energy use and $\mathrm{CO}_{2}$ emissions in that notable period.

This paper demonstrates that the method serves as an elementary but powerful tool for empirical studies. In addition, it may provide some microtheoretical foundation for conventional 
methods. Griliches (1996) has mentioned that all the pioneers of this subject were clear about the tenuousness of the estimation of technological change. This caution remains true for our method as well; for example, one of the limitations of the method is that it employs a deterministic procedure. The method could be more beneficial if used complementarily with other conventional methods.

\section{Acknowledgement}

This research was supported by the Grant-in-Aid for Scientific Research and the Asahi

Glass Foundation. The name order is alphabetical. 


\section{References}

Ang BW, Zhang FQ. A survey of index decomposition analysis in energy and environmental studies. Energy 2000; 25(12); 1149-1176.

Bacharach M. Biproportional matrices \& input-output change. Cambridge University Press: Cambridge; 1970.

Casler S, Rose A. Carbon dioxide emissions in the U.S. economy: A structural decomposition analysis. Environmental and Resource Economics 1998; 11(3-4); 349-363.

Dawkins C, Srinivasan TN, Whalley J 2001. Calibration. In: Heckman JJ, Leamer E (Eds), Handbook of econometrics, vol.5. Elsevier: New York; 2001. p. 3653-3703.

Denison EF. Why growth rates differ. The Brookings Institution: Washington DC; 1967.

Griliches Z. The discovery of the residual. Journal of Economic Literature 1996; 34(3); 1324-1330.

Harberger AC. The incidence of the corporation income tax. Journal of Political Economy 1962; 70(3); 215-240.

Hoekstra R. Economic growth, material flows and the environment: New applications of structural decomposition analysis and physical input-output tables. Edward Elgar: Cheltenham; 2005.

Hoekstra R, van den Bergh JCJM. Structural decomposition analysis of physical flows in the economy. Environmental and Resource Economics 2002; 23(3); 357-378.

Hoekstra R, van den Bergh JCJM. Comparing structural and index decomposition analysis. Energy Economics 2003; 25(1); 39-64.

IEA (International Energy Agency). IEA statistics 1998. OECD/IEA: Paris; 1999. 
Ito K, Murota Y. A macro economic modeling by using translog cost function. Journal of Japan Economic Research 1984; 13; 31-41 (in Japanese).

Jorgenson DW, Griliches Z. The explanation of productivity change. Review of Economic Studies 1967; 34(3); 249-283.

Kagawa S, Inamura H. A structural decomposition of energy consumption based on a hybrid rectangular input-output framework: Japan’s case. Economic Systems Research 2001; 13(4); 339-363.

Mansur A, Whalley J 1984. Numerical specification of applied general equilibrium models: Estimation, calibration, and data. In: Scarf HE, Shoven JB (Eds), Applied general equilibrium analysis. Cambridge University Press: Cambridge; 1984. p. 69-127.

MITI (Ministry of International Trade and Industry). White paper on international trade, Japan. Printing Bureau, Ministry of Finance: Tokyo; 1985.

Okushima S, Tamura M. Multiple calibration decomposition analysis: Energy use and carbon dioxide emissions in the Japanese economy, 1970-1995. Energy Policy 2007; 35(10); 5156-5170.

Rose A 1999. Input-output structural decomposition analysis of energy and the environment. In: van den Bergh JCJM (Ed), Handbook of environmental and resource economics. Edward Elgar: Cheltenham; 1999. p. 1164-1179.

Rose A, Casler S. Input-output structural decomposition analysis: A critical appraisal. Economic Systems Research 1996; 8(1); 33-62.

Shoven JB, Whalley J. Applied general-equilibrium models of taxation and international trade: An 
introduction and survey. Journal of Economic Literature 1984; 22(3); 1007-1051.

Shoven JB, Whalley J. Applying general equilibrium. Cambridge University Press: Cambridge; 1992.

Solow RM. Technical change and the aggregate production function. Review of Economics and Statistics 1957; 39(3); 312-320.

Tokutsu I. Econometric analysis of production structure. Sobunsha Publishing Co.: Tokyo; 1994 (in Japanese).

Tokutsu I. On a classification of technical progress. Journal of Political Economy and Commercial Science 1998; 177(4); 51-63 (in Japanese). 
Table 1 Technological change (percentage changes) when $\sigma=0$

Table 2 Technological change (percentage changes) when $\sigma=0.5$

Table 3 Technological change (percentage changes) when $\sigma=1$

Table 4 Decomposition of the change in $\mathrm{CO}_{2}$ emissions from 1970 to 1985 when $\sigma=0$

Table 5 Comparison of the results: Contribution of technological change to the change in $\mathrm{CO}_{2}$ emissions

Fig. 1. The method

Fig. 2. Contribution of technological change to the change in $\mathrm{CO}_{2}$ emissions between 1970 and 1985 when varying the substitution elasticity 


\section{Table 1}

Technological change (percentage changes) when $\sigma=0$

\begin{tabular}{lrrrrr}
\hline Input & \multicolumn{1}{l}{ Sector } & & & \\
\cline { 2 - 6 } & \multicolumn{1}{c}{ AGM } & \multicolumn{1}{c}{ EII } & \multicolumn{1}{c}{ MAC } & \multicolumn{1}{c}{ OMF } & \multicolumn{1}{c}{ SER } \\
\hline AGM & $-5.8 \%$ & $-60.3 \%$ & $-70.8 \%$ & $-12.1 \%$ & $-35.0 \%$ \\
EII & $30.8 \%$ & $-6.9 \%$ & $-78.2 \%$ & $23.4 \%$ & $-18.3 \%$ \\
MAC & $-64.5 \%$ & $-273.3 \%$ & $5.6 \%$ & $-1.8 \%$ & $19.3 \%$ \\
OMF & $-1.6 \%$ & $-23.5 \%$ & $-85.0 \%$ & $-4.6 \%$ & $-36.5 \%$ \\
SER & $53.7 \%$ & $9.0 \%$ & $-26.1 \%$ & $28.1 \%$ & $11.4 \%$ \\
COAL & $-232.7 \%$ & $-57.0 \%$ & $-233.9 \%$ & $-118.5 \%$ & $-45.2 \%$ \\
OIL & $-67.8 \%$ & $-35.4 \%$ & $-150.2 \%$ & $-48.6 \%$ & $-67.6 \%$ \\
GAS & $11.7 \%$ & $-39.4 \%$ & $-115.3 \%$ & $95.4 \%$ & $34.7 \%$ \\
ELC & $0.1 \%$ & $-5.4 \%$ & $-6.2 \%$ & $30.0 \%$ & $17.4 \%$ \\
$K$ & $35.0 \%$ & $20.0 \%$ & $-15.7 \%$ & $71.5 \%$ & $50.8 \%$ \\
$L$ & $-80.4 \%$ & $-64.4 \%$ & $-128.6 \%$ & $-35.7 \%$ & $-29.9 \%$ \\
\hline
\end{tabular}

Note: Classifications are as follows.

AGM: Agriculture, forestry, fishery, and mining, EII: Energy-intensive industry (paper and pulp, chemical, ceramics, and iron and steel), MAC: Machinery, OMF: Other manufacturing, SER: Services and others (including construction), COAL: Coal and coal products, OIL: Oil and oil products, GAS: Gas, ELC: Electricity, K: Capital, L: Labor. 


\section{Table 2}

Technological change (percentage changes) when $\sigma=0.5$

\begin{tabular}{lrrrrr}
\hline Input & \multicolumn{1}{l}{ Sector } & & & \\
\cline { 2 - 6 } & \multicolumn{1}{c}{ AGM } & \multicolumn{1}{c}{ EII } & \multicolumn{1}{l}{ MAC } & \multicolumn{1}{c}{ OMF } & \multicolumn{1}{c}{ SER } \\
\hline AGM & $-5.8 \%$ & $-56.6 \%$ & $-45.6 \%$ & $-21.9 \%$ & $-42.6 \%$ \\
EII & $27.2 \%$ & $-6.9 \%$ & $-56.7 \%$ & $10.0 \%$ & $-29.5 \%$ \\
MAC & $-89.7 \%$ & $-294.9 \%$ & $5.6 \%$ & $-36.8 \%$ & $-13.5 \%$ \\
OMF & $8.1 \%$ & $-10.1 \%$ & $-50.1 \%$ & $-4.6 \%$ & $-34.3 \%$ \\
SER & $61.3 \%$ & $20.3 \%$ & $6.8 \%$ & $26.0 \%$ & $11.4 \%$ \\
COAL & $-211.4 \%$ & $-32.1 \%$ & $-187.4 \%$ & $-106.9 \%$ & $-31.5 \%$ \\
OIL & $-17.5 \%$ & $18.5 \%$ & $-74.7 \%$ & $-8.0 \%$ & $-25.0 \%$ \\
GAS & $28.3 \%$ & $-19.1 \%$ & $-73.4 \%$ & $102.3 \%$ & $43.7 \%$ \\
ELC & $27.5 \%$ & $25.7 \%$ & $46.4 \%$ & $47.6 \%$ & $37.2 \%$ \\
$K$ & $8.3 \%$ & $-3.1 \%$ & $-17.2 \%$ & $35.1 \%$ & $16.4 \%$ \\
$L$ & $-45.4 \%$ & $-25.7 \%$ & $-68.4 \%$ & $-10.3 \%$ & $-2.5 \%$ \\
\hline
\end{tabular}

Note: Classifications are the same as in Table 1. 


\section{Table 3}

Technological change (percentage changes) when $\sigma=1$

\begin{tabular}{lrrrrr}
\hline Input & \multicolumn{1}{l}{ Sector } & & & \\
\cline { 2 - 6 } & \multicolumn{1}{c}{ AGM } & \multicolumn{1}{c}{ EII } & \multicolumn{1}{c}{ MAC } & \multicolumn{1}{c}{ OMF } & \multicolumn{1}{c}{ SER } \\
\hline AGM & $-5.8 \%$ & $-53.0 \%$ & $-20.4 \%$ & $-31.6 \%$ & $-50.2 \%$ \\
EII & $23.5 \%$ & $-6.9 \%$ & $-35.1 \%$ & $-3.4 \%$ & $-40.8 \%$ \\
MAC & $-114.9 \%$ & $-316.4 \%$ & $5.6 \%$ & $-71.8 \%$ & $-46.4 \%$ \\
OMF & $17.9 \%$ & $3.3 \%$ & $-15.1 \%$ & $-4.6 \%$ & $-32.2 \%$ \\
SER & $69.0 \%$ & $31.6 \%$ & $39.6 \%$ & $23.9 \%$ & $11.4 \%$ \\
COAL & $-190.1 \%$ & $-7.2 \%$ & $-140.9 \%$ & $-95.4 \%$ & $-17.9 \%$ \\
OIL & $32.8 \%$ & $72.5 \%$ & $0.8 \%$ & $32.5 \%$ & $17.7 \%$ \\
GAS & $45.0 \%$ & $1.2 \%$ & $-31.6 \%$ & $109.2 \%$ & $52.8 \%$ \\
ELC & $54.9 \%$ & $56.7 \%$ & $99.0 \%$ & $65.3 \%$ & $56.9 \%$ \\
$K$ & $-18.4 \%$ & $-26.1 \%$ & $-18.7 \%$ & $-1.4 \%$ & $-17.9 \%$ \\
$L$ & $-10.3 \%$ & $13.0 \%$ & $-8.1 \%$ & $15.0 \%$ & $25.0 \%$ \\
\hline
\end{tabular}

Note: Classifications are the same as in Table 1. 
Table 4

Decomposition of the change in $\mathrm{CO}_{2}$ emissions from 1970 to 1985 when $\sigma=0$

\begin{tabular}{|c|c|c|c|c|c|c|c|}
\hline \multirow[t]{2}{*}{ Components } & \multicolumn{4}{|c|}{ KLEM effects } & \multirow{2}{*}{$\begin{array}{c}\text { Final } \\
\text { demand } \\
\text { effect }\end{array}$} & \multirow{2}{*}{$\begin{array}{c}\text { Interaction } \\
\text { effect }\end{array}$} & \multirow[t]{2}{*}{ Total } \\
\hline & $\begin{array}{c}\text { Capital } \\
\text { TC(=CFI })\end{array}$ & $\begin{array}{c}\text { Labor } \\
\text { TC }(=\text { CFI })\end{array}$ & $\begin{array}{c}\text { Energy } \\
\text { TC }(=\text { CFI })\end{array}$ & $\begin{array}{c}\text { Material } \\
\text { TC }(=\mathrm{CFI})\end{array}$ & & & \\
\hline $\begin{array}{l}\text { Change in } \mathrm{CO}_{2} \\
\text { emissions [Mt-C] }\end{array}$ & 51.8 & -26.9 & -1.7 & 35.6 & 69.5 & -82.5 & 45.7 \\
\hline
\end{tabular}


Table 5

Comparison of the results: Contribution of technological change to the change in $\mathrm{CO}_{2}$ emissions

\begin{tabular}{lcc}
\hline & This paper & Okushima and Tamura (2007) \\
\hline Period & $1970-85$ & $1970-95$ \\
\hline MMt-C] & $-28.0 \sim 51.8$ & 132.8 \\
Capital TC & $-26.9 \sim 8.7$ & -37.5 \\
Labor TC & $-1.7 \sim 28.2$ & -16.1 \\
Energy TC & $-20.1 \sim 35.6$ & 53.5 \\
Material TC &
\end{tabular}




\section{Factor input}

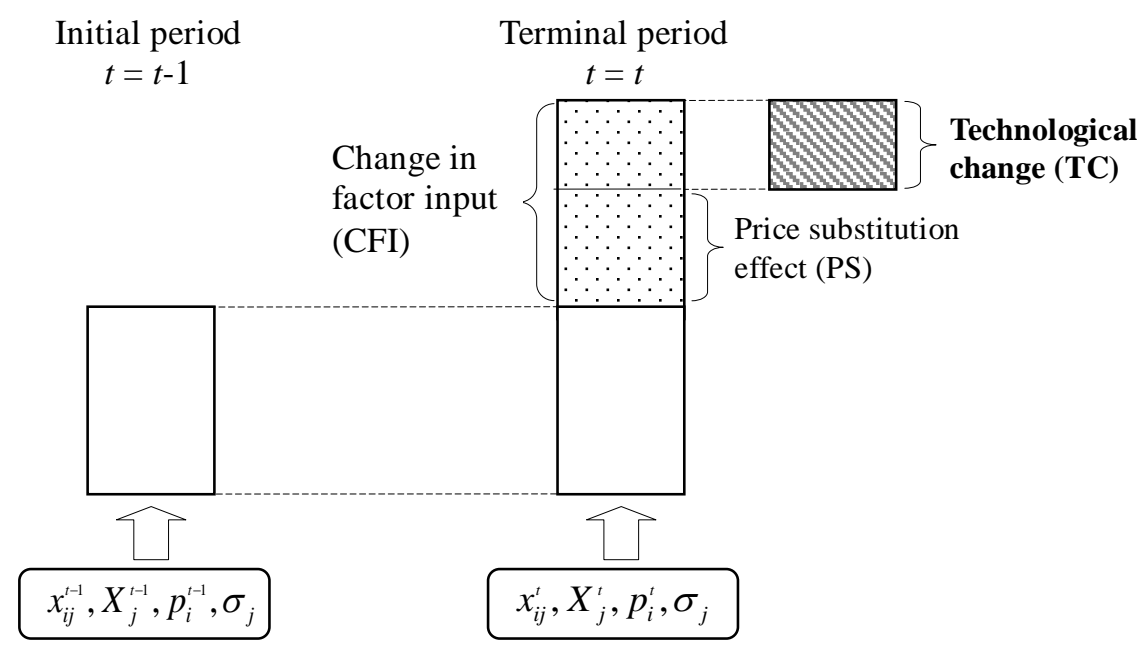

Fig. 1. The method 


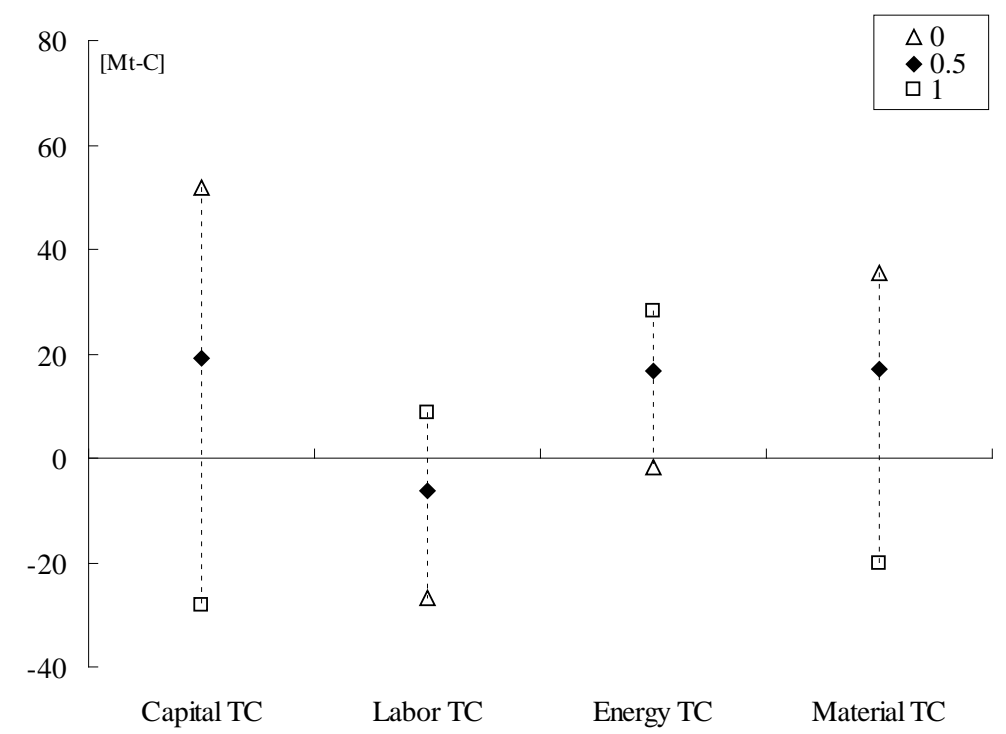

Fig. 2. Contribution of technological change to the change in $\mathrm{CO}_{2}$ emissions between 1970 and 1985 when varying the substitution elasticity 